\title{
Overweight and obesity among mothers of malnourished children - Brazil - PNSN - 1989
}

\author{
Universidade Federal de São Paulo/Escola Paulista de Medicina - São Paulo, Brazil
}

\begin{abstract}
Objective: To evaluate the relationship between the nutritional status of the youngest child under 48 months of age (in families with the biological mother present) and their mothers among 3906 children selected from a sample of a national survey in 1989 (PNSN). Results: Malnutrition was present in 5.8\% of the children. From these, $21.8 \%, 60.9 \%$ and $17.3 \%$ had overweight/obese, eutrophic and malnourished mothers, respectively. Stratified analyses taking into account the regions, situation, income distribution and mother's educational level demonstrated that a lower proportion of malnourished children was concurrent with a higher proportion of overweight/obese mothers. The Kappa test evidenced a poor agreement between the nutritional conditions of the child-mother pairs $(\mathrm{K}<=0.048)$. Conclusions: When the proportion of malnourished children decreased within the analyzed groups, the proportion of overweight/obese mothers increased. Such an epidemiological pattern indicates that within groups in which malnutrition is less prevalent, the proportion of children for whom a lack of food in the household is the main determinant factor for malnutrition is lower.
\end{abstract}

Uniterms: Child's nutrition. Mother's nutrition. Anthropometry. Nutritional inquiries.

\section{INTRODUCTION}

$\mathrm{T}$ The first years of life are fundamental and critical for future development, since growth retardation represents a manifestation of a more general syndrome which includes physical and mental effects as well as brain damage, which can often be irreversible and impair all further cognitive processes. ${ }^{1}$ Hence, adequate nutrition is essential for appropriate development and good

\section{Address for correspondence:}

Eliana Monteiro Rodrigues

Rua Marselhesa, 630

São Paulo/SP - Brasil - CEP 04020-060 health, thus not only affecting the biological sphere, but also the social and productive sphere of society as a whole.

A child with retarded growth, as well as developing diseases more often and for longer periods, may also present a lower intelligence quotient, giving rise to a worse performance at school, higher indices of school failure and abandonment, and consequently becoming a less productive adult with a decreased physical and mental capacity for work. ${ }^{2}$ All things considered, such an adult will generally end up in badly-paid jobs or just surviving on subemployment, leading to the perpetuation of the "poverty syndrome" into the next generation. Thus, he replicates with his own children the precarious conditions which he grew up in, characterized by low levels of income and education, insufficient food intake, inadequate housing conditions with absence of basic sanitation, thereby also 
generating a higher incidence of infections. Thus, a vicious circle is created which needs to be broken. ${ }^{3}$

For this vicious circle to be interrupted, one of the major issues to be considered is the food assurance at the household level. This constitutes a priority action area for malnutrition control in the 1990's. ${ }^{3}$ Food assurance would give all members of the family access to the foods necessary for a healthy life, without the stress caused by the risk of losing this access. This would include social support to enable a minimal quality of life, especially for the less-privileged social strata of the population. ${ }^{4}$ However, food assurance should not be seen as the only factor for nutritional improvement. As Mc Guire ${ }^{2}$ pointed out, growth retardation is not only caused by poverty, noting that half of all poor children present adequate growth.

Policies aimed at improving the population's nutrition and health which are to have any chance of reaching their objectives should include the control of parasitical and infectious diseases, basic sanitation and primary health care, breast-feeding incentives, prevention of low birthweight via care given during gestation (pre-natal follow-up) and family planning (to increase the intergenetic interval and prevent undesired pregnancies). ${ }^{3,5}$

Family dynamics also deserves special attention, especially with regard to factors related to the mother's capacity and availability to adequately take care of her child. These factors are called "maternal technology" by Mata and comprise knowledge and practice of suitable preparation and administration of food, recognition of dehydration signals and perception of the value of vaccination and basic health care. There is evidence that this "maternal technology" can often be more relevant in the prevention of malnutrition than socio-economic factors. ${ }^{6}$

Apart from organic processes, it is vitally important to understand that young children, especially infants, need much more than the essential feeding and hygiene care in order to have healthy development. Establishing an early mother-child bond is also extremely important, since the child is dependent on getting enough attention and affection for its adequate development. Several studies report that a weak or inexistent link between mother and child may affect the child's nutritional status. Moreover, certain repeated infections seem to be connected with defective relationships. These studies conclude that a good relationship is a factor that may protect the child from malnutrition, even in cases of low food consumption. ${ }^{7}$

It is worth highlighting those few studies which consider the family as the research unit and which may show the relationship between the nutritional status of the children and their families or mothers. A recent study conducted in a Brazilian outpatient population (2236 children and 2067 mothers of low socio-economic level attended to in the pediatric clinic of the Escola Paulista de Medicina, in the city of São Paulo $)^{8}$ demonstrated that the malnourished child can have an eutrophic mother (54.2\% of the cases) or even an obese mother $(30.5 \%$ of the mothers were overweight or obese), and that the mother's educational level could be influencing the nutritional status of the child. Within this study, no association between the nutritional status of the children and their mothers was encountered. Thus, the lack of opportunity, leading to a lack of information and resulting in nutritional deviations, would be the major factor in the genesis of malnutrition. In childhood, malnutrition would frequently be due to wrong food choices and repeated infections; while in adult life, hypercaloric diets through the years would lead to overweight and obesity.

\section{OBJECTIVES}

The present study describes and analyses the nutritional profile of children younger than 48 months, correlating them with their mothers' nutritional conditions within the different ambits of the Brazilian population, as defined by the National Survey on Health and Nutrition (Pesquisa Nacional de Saúde e Nutrição - PNSN), focusing on the malnourished child. It also investigates potential correlations between the nutritional condition of these children and their mothers in relation to per capita household income, maternal age and educational level.

\section{METHODS}

The National Survey on Health and Nutrition (Pesquisa Nacional sobre Saúde e Nutrição - PNSN), an anthropometric study conducted across the whole nation in 1989, had as its main goal the assessment of the nutritional status of the Brazilian population by means of the collection of anthropometric data. It was a transversal, domicile-based study performed by the Instituto Nacional de Alimentação e Nutrição - INAN, together with the Fundação Instituto Brasileiro de Geografia e Estatística - IBGE and the Instituto de Pesquisa Econômica Aplicada - IPEA. ${ }^{9,10}$

The sampling of the PNSN was designed to provide representative estimates of the Brazilian population resident in private and collective homes, with the exception of people living in barracks, hospitals, homes for old 
people, hotels and similar establishments, and Indian settlements. ${ }^{9,11}$

The main activities of the PNSN were centered on determining weight and length/height measurements. A portable microelectronic scale (Filizola, Brazil) with a capacity of $150 \mathrm{~kg}$ and precision of $100 \mathrm{~g}$ was adopted for the determination of the adults' and children's weights. The weight was registered in $\mathrm{kg}$ and one decimal unit. Height measures were determined by a French unextendable tapeline with a precision of $0.1 \mathrm{~cm}$ affixed to a plane vertical surface in the home of the interviewees. Heights were registered in $\mathrm{cm}$ and one decimal unit. To determinate the length of small children up to $100 \mathrm{~cm}$, a Brazilian anthropometric ruler with a precision of $0.1 \mathrm{~cm}$ was employed. ${ }^{10}$

The present study consists of a subdivision of the PNSN sample. From the 6015 children under the age of 48 months forming part of the "children" file in the original survey database, the ones presenting complete anthropometric data (5864) were selected. For the present analysis, the following children's records were excluded: children whose mothers were pregnant (510), children who did not live with their biological mothers (302), were twins (108) or whose mothers' anthropometric data were not available (38). Elder brothers or sisters below the age of 48 months were also excluded (994), thus taking into consideration solely the youngest child of each woman. While collecting data, children whose mothers' pregnancy condition was unknown (6) were also disregarded.

Thus, only the youngest child, called the index child, was considered when the mother had more than one child under 48 months of age; thus totalling 3,906 children.

All the details concerning data collection, transcription and creation of indicators are duly described in specific documentation of the PNSN. ${ }^{9,10}$

The reference standard of the National Center for Health Statistics (NCHS) of the USA, recommended by the World Health Organization, was adopted for classifying the children's nutritional status via the measurement of weight and height/length, sex and age in months. Thus, those children with a weight/age index (WAZ) below $-2.00 \mathrm{Z}$ were considered as malnourished, between -2.00 and $+2.00 \mathrm{Z}$ as eutrophic, and over $+2.00 \mathrm{Z}$ as obese, using the Z-score criterion. $^{12}$

The FAO criteria were used for the mothers, based upon weight and height measurements, deriving the Quetelet index (biological mass index or body mass index - BMI), defined as weight in kilograms $(\mathrm{kg})$ divided by height in square meters $\left(\mathrm{m}^{2}\right)$. Thus, those women with Quetelet index up to 18.69 were considered as malnourished, between 18.70 and 23.89 as eutrophic, between 23.90 and 28.59 as overweight, and above 28.59 as obese. ${ }^{13}$ For this analysis, overweight and obesity were grouped together.

The domiciles were grouped according to administrative divisions currently adopted: Brazilian macro-regions (North, North-East, South-East, South and Middle-West) and situation (urban and rural).

The mother's educational level ranged from 0 (illiterate) to 17 years of study (corresponding to a university graduate) within the original database, which for this analysis was divided into two groups (up to or more than 3 years of study), established from the median of the primary distribution.

As regards data on the total household income and number of tenants, the original database had already demonstrated varying per capita household income, measured at the official dollar exchange rate of the day of the survey. In the present study, three classes of income were considered: below US\$25.00, between US\$ 25.00 and US\$ 50.00 and greater than or equal to US\$ 50.00.

Concerning maternal age, from the age information in years in the database, 2 age groups were defined based on the median age: up to and above 24 years of age.

In order to compare the nutritional status of the index children and their mothers, the Kappa concordance test $\mathrm{t}^{14}$ was employed, which was analysed in conformity with concordance classes, as follows: below 0.00 , bad; between 0.00 and 0.20 , weak; between 0.21 and 0.40 , tolerable; between 0.41 and 0.60 , reasonable; between 0.61 and 0.80 , good; between 0.81 and 0.99 , very good and 1.00 , perfect. ${ }^{15}$ The data tabulation also included the chi-square test to evaluate associations. ${ }^{16}$

For all the tests, the significance level was set at 0.05 or $5 \%$ for the rejection of the null hypothesis.

\section{RESULTS}

The two maps demonstrated in Figure 1 present the percentages of malnourished children in urban and rural domicile situations in each Brazilian region. It may be observed that the only region that maintains the same pattern of infantile malnutrition independently of the situation is the Middle-West. The patterns of malnutrition encountered in the rural areas of the South, South-East and North-East of Brazil are all worse. The most extreme effect is found in the South-Eastern region, where malnutrition rises from less than 3\% in the urban area to between 5 and $7 \%$ in the rural area, the latter being similar to the percentage encountered in the urban North-East. Conversely, in 1989 the urban populations of the South 


\section{URBAN BRAZIL}

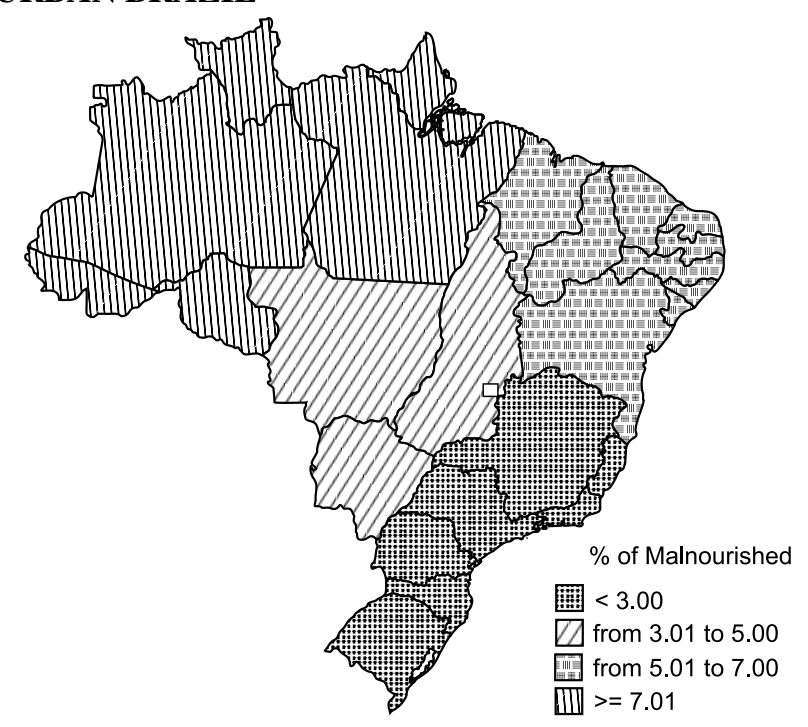

RURAL BRAZIL

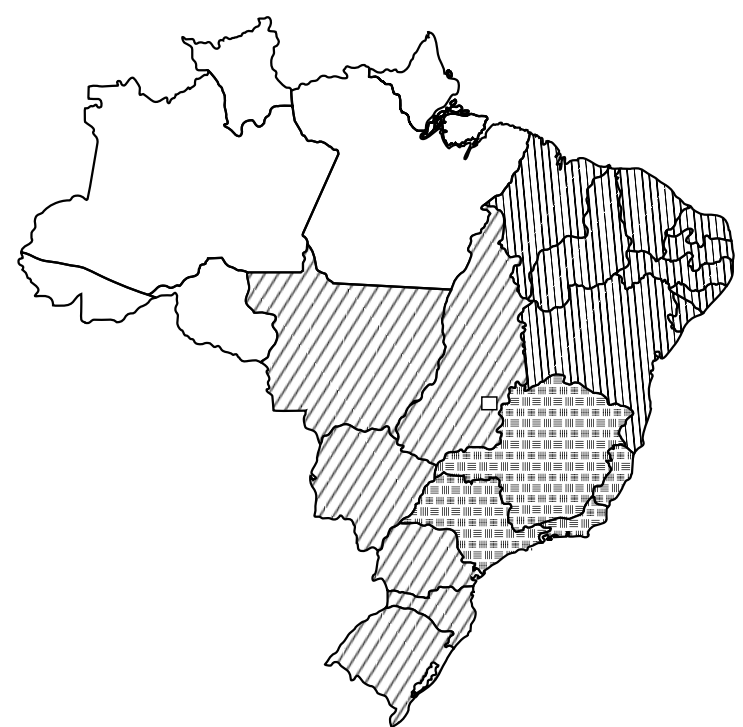

P.S.: There is no information regarding the rural Northern Region.

Figure 1 - Distribution of the malnourished index-children - Brazil - PNSN - 1989.

and South-East presented proportions of children with anthropometric weight/age deficits comparable to the ones observed in the reference population.

In Table 1, a positive association between the nutritional condition of the index children and their mothers is demonstrated. Malnutrition was present among $8 \%$ of the mothers, and among the malnourished index children, the percentage of mothers also presenting a nutritional deficit was $17.3 \%$. At the other extreme of the classification, $36.7 \%$ of the mothers presented obesity or overweight. The latter tended to have preponderantly obese children, as $50 \%$ of obese children's mothers were overweight or obese.
However, $82.7 \%$ of the malnourished children had eutrophic mothers or mothers presenting some degree of obesity. Similarly, $50 \%$ of the obese children had mothers belonging to eutrophic or malnourished groups. The test measuring concordance levels demonstrated weak concordance between the two distributions (Kappa $=$ $0.024)$.

Figures 2, 3 and 4 present the proportions of malnourished children and malnourished children's mothers who were overweight or obese according to independent variables: household situation and region, per capita household income, maternal age, mother's educational level and the index child's age. On the whole, when the proportion of malnourished children diminished within a specific analysis group, the proportion of mothers presenting obesity or overweight increased, thus establishing a pattern.

The Kappa test was applied to the distributions for each of the analysis categories presented in Figures 2 to 4 and a weak degree of concordance between the nutritional conditions of the index children and their mothers was demonstrated ( $\mathrm{K}$ between -0.005 and 0.048 ).

\section{DISCUSSION}

In Figure 2, it can be observed that data on the youngest children (index children) in families made up of at least the mother and child under 4 years of age, according to the selection conditions of the analysed sub-sample, was in agreement with previous studies which reported that in Brazil the percentage of malnourished children below the age of 5 (below $-2.00 \mathrm{Z}$ ) is approximately $5.1 \% .{ }^{17}$ This proportion was lower in urban situations than in rural ones (4.8 against $6.9 \%$ ), as well as being higher in less developed regions of the country (North and North-East). As reported in the preliminary results of the PNSN, the present sub-sample also encountered the highest rates of infantile malnutrition in the North-Eastern region (10\%), and the Northern region presented similar proportions. The Middle-West gave an intermediate nutritional picture similar to what was observed in the South-East (around $4 \%$ ), and the South was the region with the most favorable situation regarding malnutrition (2.4\%). Although reaching concordant results, it must be emphasized that the malnutrition values established here are always superior to the ones presented in the preliminary data, ${ }^{17}$ possibly owing to the fact that different age groupings were considered. The 1990 analyses grouped together all the children under the age of 60 months, while the statistics 
Table 1

Distribution of the index-children in WAZ categories according to the maternal BMI Brazil - PNSN - 1989

\begin{tabular}{|c|c|c|c|c|c|c|c|c|}
\hline \multirow{3}{*}{$\begin{array}{l}\text { WAZ Categories } \\
\text { Malnourished }\end{array}$} & \multicolumn{8}{|c|}{ Maternal BMI } \\
\hline & \multicolumn{2}{|c|}{ Malnourished } & \multicolumn{2}{|c|}{ Eutrophic } & \multicolumn{2}{|c|}{ Overweight + Obese } & \multicolumn{2}{|c|}{ Total } \\
\hline & 39 & (17.3) & 137 & $(60.9)$ & 49 & $(21.8)$ & 225 & [5.8] \\
\hline Eutrophic & 266 & $(7.6)$ & 1947 & (55.4) & 1300 & (37.0) & 3513 & {$[89.9]$} \\
\hline Obese & 6 & (3.6) & 78 & (46.4) & 84 & $(50.0)$ & 168 & [4.3] \\
\hline Total & 311 & (8.0) & 2162 & (55.4) & 1433 & (36.7) & 3906 & \\
\hline
\end{tabular}

( ) Percentagens in relation to the line

[ ] Percentagens in relation to the column

$$
\begin{aligned}
& X^{2}=55.27^{*} \\
& D F=4 \\
& p<0.00000001
\end{aligned}
$$

$$
\begin{aligned}
& \text { Kappa }=0.0244 \\
& { }_{\text {calc }} Z=3.0999 \\
& { }_{\text {crit }} Z=1.64 \\
& p=0.0010
\end{aligned}
$$

presented here give the proportion of malnutrition in a group up to the age of 47 months. Malnutrition between 47 and 60 months is recognizably less prevalent than in younger groups. ${ }^{18}$

As previously emphasized, a lower proportion of malnourished children was generally associated with a higher proportion of malnourished children's mothers presenting overweight or obesity. One possible explanation is that where infantile malnutrition is less prevalent, malnutrition is mainly determined by factors not linked with household food availability. A lack of knowledge concerning health and nutrition could lead to mistaken food habits and inadequate use of health services, factors that sinergically would promote both maternal obesity and infantile malnutrition. The only exception to this inverse correlation between infantile malnutrition and maternal obesity was obtained in the Northern region, where the lack of data from the rural area should have distorted this tendency.

In the same way as was observed for the regions and situations (Fig. 2), a decrease in the percentage of malnourished index children may be observed where either the per capita household income or the mother's educational level improved (Fig. 3).

Comparing the extremes of each situation (higher and lower incomes, and the two educational levels), the malnutrition rate in children dropped more than threefold when the best socio-economic-educational conditions were available (reaching a fivefold drop relating to income). In any situation, the decrease in the proportion of malnourished children was always associated with a higher proportion of overweight/obese mothers.

The same reasoning developed above to explain variations in infantile malnutrition and maternal obesity according to region and urban or rural situation can be applied to income and educational level variations.
Malnourished children who belonged to higher-income families and children whose mothers had a higher educational level would not preponderately have a lack of food in the household as the determinant factor in malnutrition. Infantile malnutrition within this group would be correlated more with the mother's knowledge, attitudes and practices relating to food and hygiene care towards the child.

Regarding maternal age, Figure 4 shows a pattern which is the inverse of the general trend found in the preceding Figures. The increase in infantile malnutrition was associated with increased maternal obesity or overweight in the 25-orolder age group. The higher proportion of obesity among older mothers is justifiable, as obesity and overweight are characterized as cumulative exposure processes, being more frequently found in older age groups. ${ }^{10}$

Nevertheless, infantile malnutrition ought to be less frequent among older mothers, since these mothers should be more informed and be in a better position to provide goods and services to maintain their children's health and nutrition.

Concerning the child's age, although lower proportions of malnutrition were associated with an increased incidence of maternal obesity and overweight, there was not a uniform gradient following the age groups. Within the youngest group (under 12 months of age), the proportion of malnourished children was lower due to shorter time of exposure to environmental risks, whereas maternal obesity and overweight were more prevalent, probably reflecting the storage of adipose tissue during pregnancy, which is prolonged during the puerperium. Within the subsequent age groups, the relationships between the proportions of infantile malnutrition and maternal obesity and overweight were in agreement with the ones observed in the previous analyses, with an increase in the latter when the former 


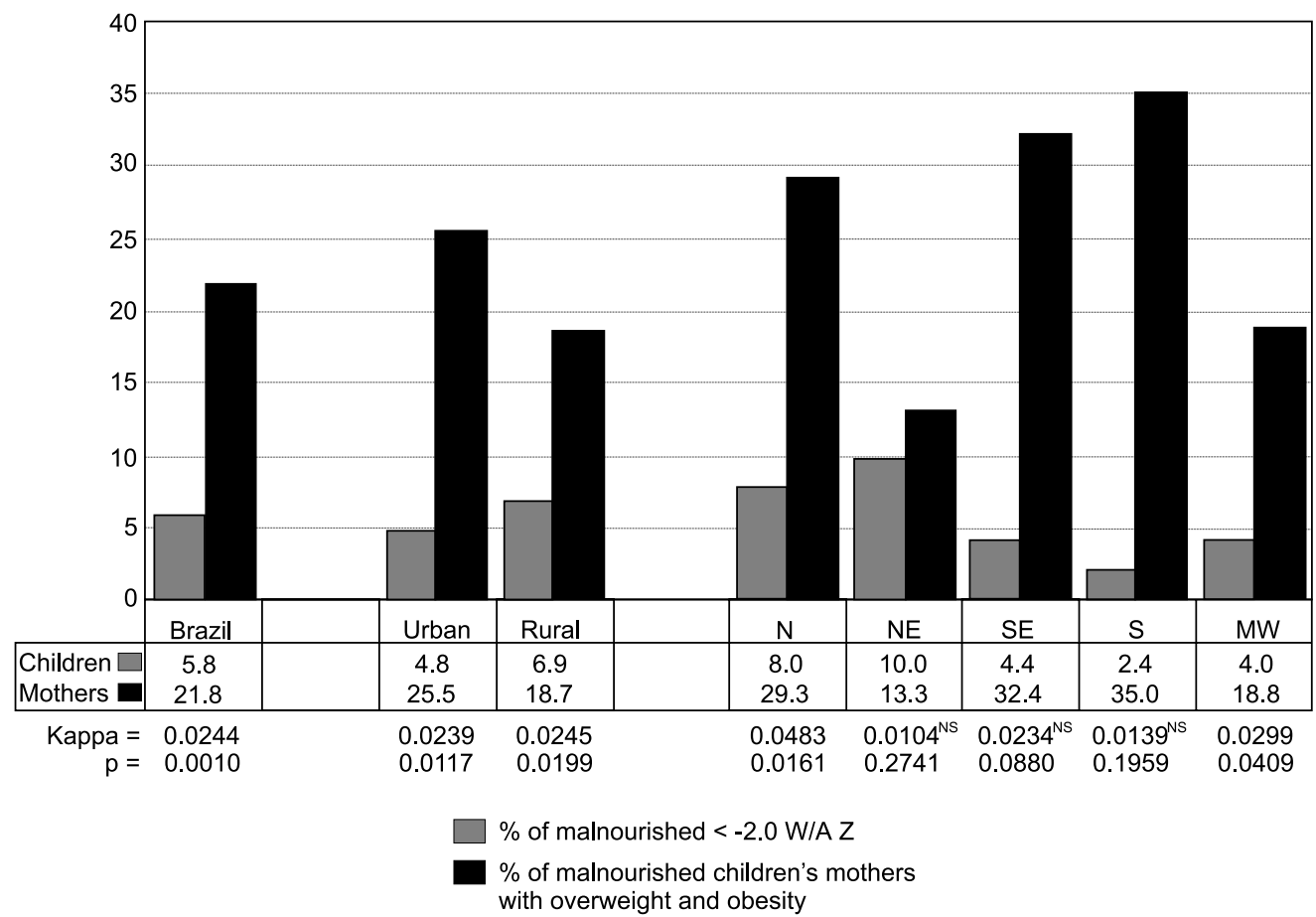

Figure 2 - Proportion of malnourished children and malnourished children's mothers with overweight and obesity according to the situation and regions.

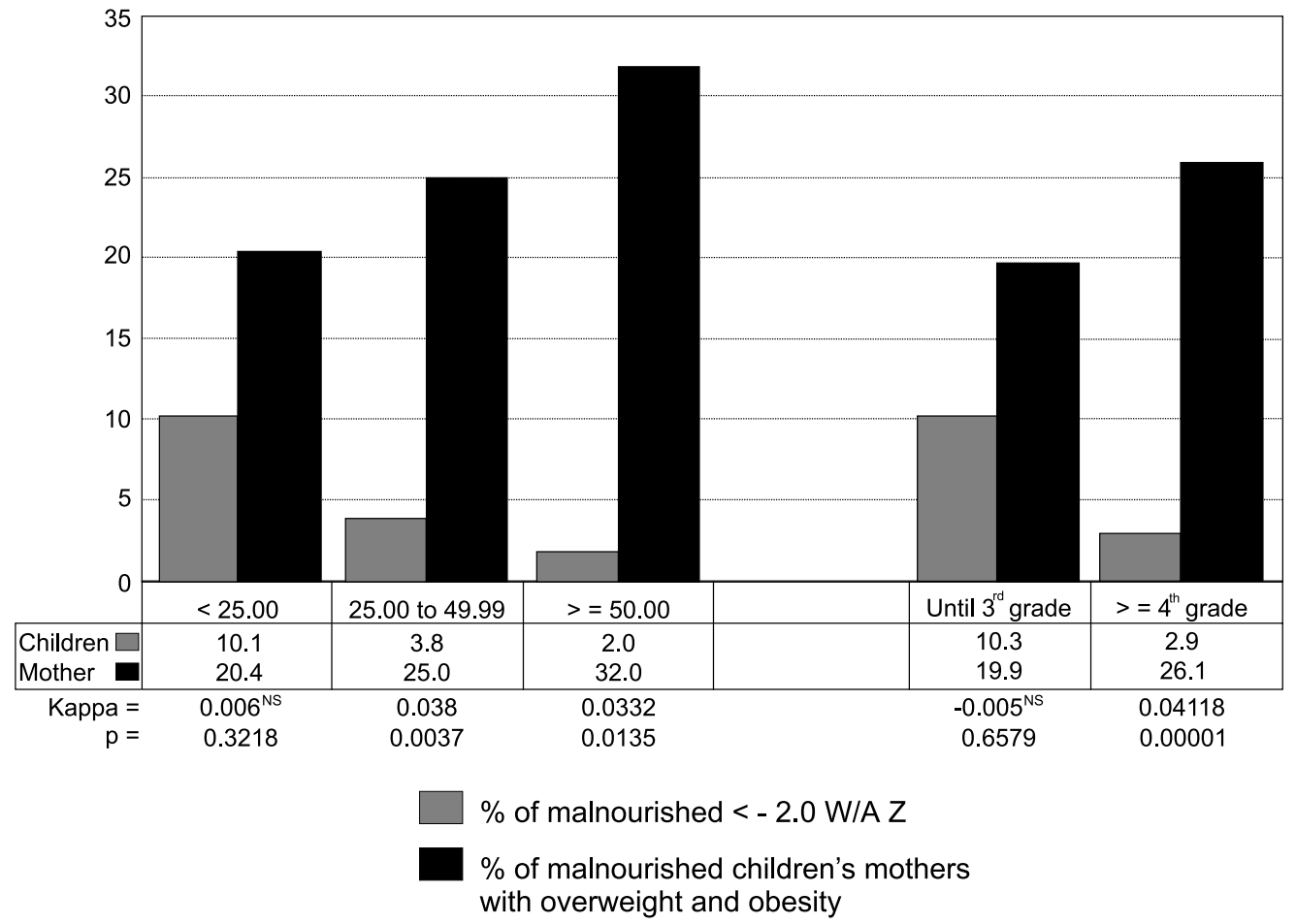

Figure 3 - Proportion of malnourished children and malnourished children's mothers with overweight and obesity according to domiciliary per capita income in US\$ and maternal scholarship 


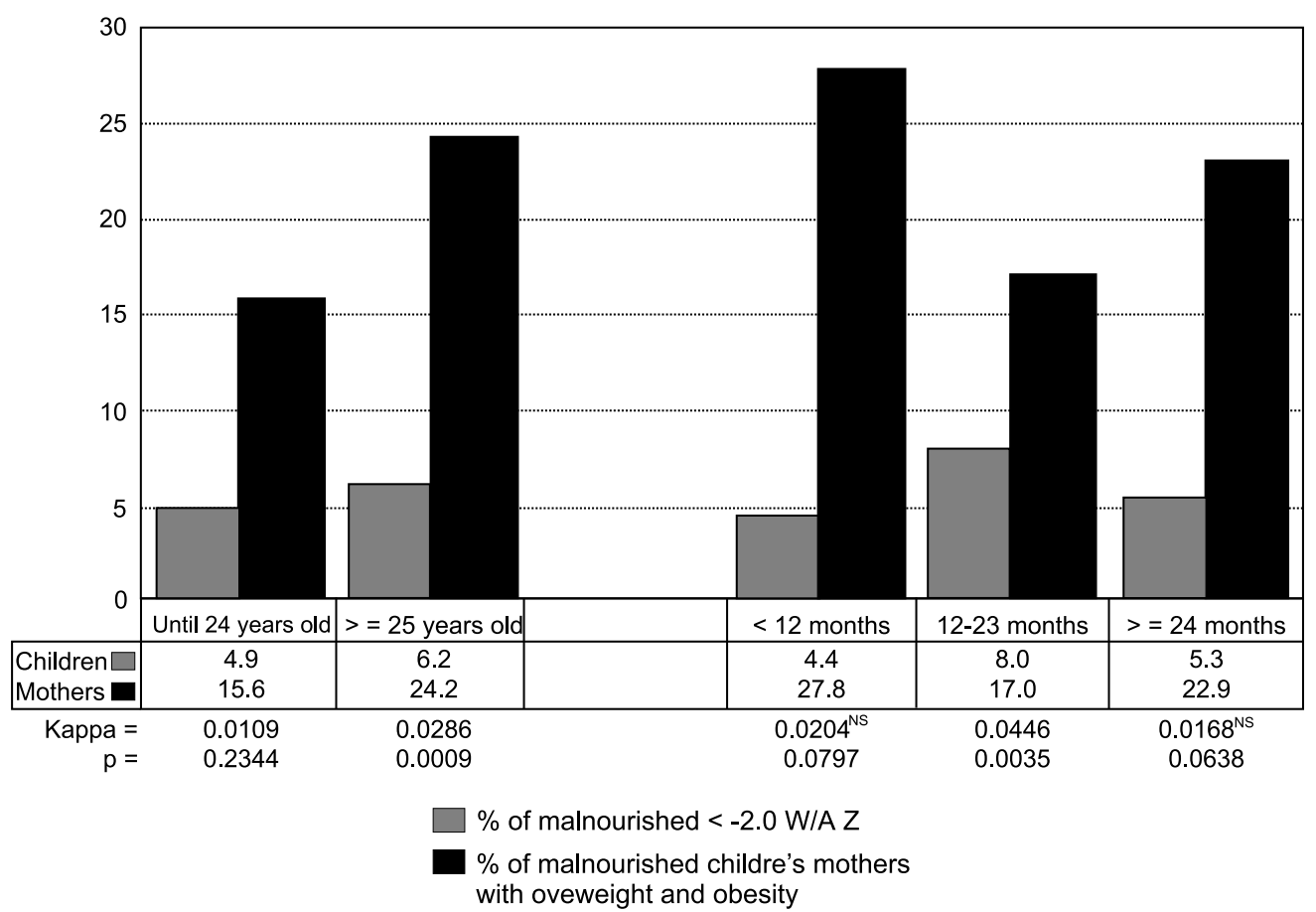

Figure 4 - Proportion of malnourished children and malnourished children's mothers with overweight and obesity according to maternal age and the index-child's age

was diminished, thus probably reflecting epidemiological patterns of infantile malnutrition and female obesity. The proportions of malnourished children were higher in the second year of life compared to the third and fourth years. Also higher were the proportions of obesity and overweight in the group of older women. The group of mothers of older children is probably older than the group of mothers of younger children. Such patterns would act in a manner associated with the mechanism previously described, to justify the increase in obesity and overweight among mothers of malnourished children when the prevalence of malnutrition was reduced.

From a statistical viewpoint, with the aim of evaluating the degree of concordance between mothers' and children's nutritional conditions, even in cases where the Kappa test results had significance, thus indicating concordance between their nutritional states, this association turned out to be weak (with $\mathrm{K}$ values ranging from -0.0050 to 0.0483 , independently of the significance), according to the interpretation table presented by Pereira. ${ }^{15}$ Therefore, for the Brazilian populations of 1989, the findings of the studies assessing outpatient populations were here reconfirmed, revealing the existence of poor agreement between the nutritional conditions of mothers and their malnourished children.

\section{CONCLUSION}

To conclude, an important point must be emphasized: approximately a quarter of malnourished children's mothers presented overweight or obesity and $60.9 \%$ were eutrophic. Therefore, only $17 \%$ of mothers were as malnourished as their children.

Knowledge built up through the years, based upon images of war refugees or starvation regions in Asia and Africa presenting mothers and their children in conditions of malnutrition, is not applicable to the condition of endemic infantile malnutrition encountered in the urban and rural areas of Brazil, where concordance between the nutritional status of children and their mothers, even when present, was very weak. Statistical concordance tests (Kappa) reinforced the above statement from a probabilistic stance.

Health professionals, when facing an overweight or obese mother in their routine clinical practice, should not conclude that infantile malnutrition is not associated to the deprivation syndrome if the mother demonstrates excessive food consumption. Maternal obesity and child malnutrition are probably consequences of common determinant factors, based upon the mother's lack of 
information and availability for feeding herself and her child correctly, as well as sometimes indicating problems in their relationship.

From the viewpoint of planning nutritional promotion activities, the importance of suitable income to enable acquisition of food that guarantees adequate nutrient intake must be reaffirmed. However, it must be noted that

\section{REFERENCES}

1. Martorell R, Rivera J, Kaplowitz H, Pollitt E. Long-term consequences of growth retardation during early childhood. In: Hernandez M, Argente J, ed: Human growth: basic and clinical aspects; 1992:143-9.

2. McGuire JS, Austin JE. Beyond survival: children's growth for national development. Assignment Child 2;1987:1-52.

3. Acc/Scn. Some options for improving nutrition in the 1990. SCN News 7 (suppl): ONU 1991.

4. Galeazzi MAM (org.). Segurança alimentar e cidadania: a contribuição das universidades paulistas. Campinas, Mercado de Letras; 1996:352.

5. Beghin I, Cap M, Dujardin B. Guia para evaluar el estado de nutricion. Washington: Organização Panamericana de la Salud; 1989 (Publicação Científica, 515).

6. Mata L. A public health approach to the food-malnutritioneconomic recession complex; 1988:265-75.

7. Nóbrega FJ, Campos ALR. Distúrbios nutricionais e fraco vínculo mãe e filho. São Paulo; 1996:31-63.

8. Nóbrega FJ, Vítolo MR, Brasil ALD, Lopez FA. Nutritional status of mothers and children: the relationship with birthweight, size of family and certain maternal variables. Children's Hospital Quarterly 4; 1992:149-55. deficiencies in the mother's knowledge and time availability which may prevent her from giving adequate care to her child are found associated with the household budget deficiency. Hence, educational action on health and nutrition aimed at mothers and labor legislation that makes it possible for mothers to take care of their children are just as important as the food assurance at the household level.

9. Instituto Nacional de Alimentação e Nutrição. Pesquisa Nacional sobre Saúde e Nutrição. Brasília; 1990:163. (Arquivo dos dados da pesquisa).

10. Instituto Nacional de Alimentação e Nutrição. Condições nutricionais da população brasileira: adultos e idosos. Brasília; 1991:39.

11. Fletcher PR. PNSN - A seleção dos elementos da amostra na segunda etapa de amostragem. Brasília: OIT1988:17. (mimeo).

12. World Health Organization. Use and interpretation of anthropometric indicators of nutritional status. Bulletin of WHO 64; 1986:929-41.

13. World Health Organization. Energy and protein requirements - WHO report of FAO/WHO/ONU expert consultation. Geneva; 1985.

14. Fleiss JI. Statistical methods for rates and proportions. New York: John Willey and Sons; 1973:223.

15. Pereira MG. Epidemiologia: teoria e prática. Rio de Janeiro: Guanabara Koogan; 1995:364-7.

16. Siegel S. Estatística não-paramétrica para as ciências do comportamento. McGraw-Hill do Brasil; 1981.

17. Instituto Nacional de Alimentação e Nutrição. Pesquisa Nacional sobre Saúde e Nutrição. Brasília; 1990:32. (Resultados preliminares).

18. World Health Organization. Physical Status: the use and interpretation of anthropometry. WHO Technical Report Series, 854. WHO: Geneva; 1995.

\section{Resumo}

Objetivos: Analisar relação entre estado nutricional das crianças mais novas menores de 48 meses (de famílias com mães biológicas presentes) e suas mães, em 3.906 crianças selecionadas da amostra de inquérito nacional realizado em 1989 (PNSN). Resultados: 5,8\% das crianças apresentavam desnutrição. Destas, 21,8\% tinham mães com sobrepeso/obesidade, $60,9 \%$ mães eutróficas e $17,3 \%$ mães desnutridas. Análises estratificadas quanto às regiões, situação, distribuição da renda e escolaridade materna, demonstram que, à menor proporção de crianças desnutridas corresponde maior proporção de mães com sobrepeso/obesidade. O teste Kappa evidenciou fraca concordância entre condições nutricionais das duplas criançasmães $(K<=0,048)$. Conclusões: Quando diminuem as proporções de desnutridos nos grupamentos analisados, aumentam as proporções de mães que apresentam sobrepeso/obesidade. Tal padrão epidemiológico indicaria que, nos grupos onde a desnutrição é menos prevalente, é menor a proporção daquelas crianças que tem a falta de alimentos em nível domiciliar como principal fator limitante na determinação da desnutrição. 